\title{
As produções do espaço associado de um autor e a embreagem paratópica: uma relação possível
}

DOI: http://dx.doi.org/10.21165/el.v49i3.2540

\section{Manuel José Veronez de Sousa Júnior ${ }^{1}$}

\section{Resumo}

Por meio do quadro teórico-metodológico da Análise do Discurso Literário engendrado por Dominique Maingueneau, consegui, em minha tese de doutorado, enquanto resultados, sustentar duas hipóteses. A partir desses resultados, propus, enquanto projeto de pesquisa pós-doutoral, apresentar e consolidar a cena genérica como um $4^{\circ}$ embreante paratópico possível, incluindo-a ao grupo dos embreantes paratópicos proposto por Maingueneau: o ethos, a cenografia e o posicionamento na interlíngua. Desse modo, a hipótese central do projeto de Pós-doutorado a ser sustentada foi de que as cartas privadas (enquanto cena genérica e espaço associado) de autores consagrados dos discursos constituintes funcionam como um embreante paratópico. Neste artigo, realizo uma das análises propostas em meu projeto, analisando uma carta privada de Sêneca (um autor do campo filosófico). Com esta análise, verifico que há indícios para sustentar a hipótese central.

Palavras-chave: cena genérica; embreante paratópico; discurso filosófico.

1 Universidade Federal de Uberlândia (UFU), Uberlândia, Minas Gerais, Brasil; veronezmanuel@gmail.com; https://orcid.org/0000-0002-8777-9859 


\title{
An author's associated space productions and the paratopic clutch: a possible relationship
}

\begin{abstract}
Through the theoretical-methodological framework of French Discourse Analysis, especially the Literary Discourse, engendered by Dominique Maingueneau, I managed, in my doctoral thesis, to support two hypotheses. From the unfolding of my doctoral thesis, I proposed, as a Postdoctoral research project, to present and consolidate the generic scene as a 4th possible paratopic clutch, including it to the group of paratopic clutches proposed by Dominique Maingueneau: ethos, a scenography and positioning in the interlanguage. The central hypothesis of this Postdoctoral project was that the private letters productions as an associated space (generic scene) by established authors of a determined (and constituent) discursive field function as a paratopic clutch. In this article, I will perform one of the analyses proposed in my project, analyzing a private letter from Seneca (an author of the philosophical field). With this analysis, I see that there is evidence to support the central hypothesis.
\end{abstract}

Keywords: generic scene; paratopic clutch; philosophical speech.

\section{Introdução}

Mobilizando o quadro teórico-metodológico da Análise do Discurso Literário engendrado por Dominique Maingueneau, consegui, em minha tese de doutorado, sustentar duas hipóteses: i) As cartas privadas de autores consagrados do campo literário funcionam como um gênero do discurso, não como um hipergênero; e ii) Essas cartas privadas, enquanto uma cena genérica (designa o gênero do discurso), funcionam também como um embreante paratópico. Na tese, para buscar sustentar as hipóteses, objetivei analisar o funcionamento da autoria, a constituição da paratopia e as cenografias construídas nas/pelas cartas privadas trocadas entre Mário de Andrade e Carlos Drummond de Andrade (autores consagrados do campo literário brasileiro do início do século XX).

A partir do desdobramento da minha tese de doutorado, sobretudo seus resultados (a sustentação das hipóteses), propus, enquanto projeto de pesquisa pós-doutoral, apresentar e consolidar a cena genérica como um $4^{\circ}$ embreante paratópico possível, incluindo-a ao grupo dos embreantes paratópicos proposto por Dominique Maingueneau: o ethos, a cenografia e o posicionamento na interlíngua. Desse modo, a hipótese central do projeto de Pós-doutorado foi de que as cartas privadas (enquanto cena genérica e espaço associado) de autores consagrados dos discursos constituintes funcionam como um embreante paratópico. 
Para sustentar essa hipótese, busquei selecionar, enquanto corpus de análise, cartas privadas de autores consagrados dos campos Filosófico, Científico e Religioso (não tratei do campo Literário no projeto de Pós-doutorado, porque ele já foi trabalhado em minha tese de doutorado (2018) de forma mais densa²) e percorri três objetivos específicos, os mesmos da tese, por uma questão de regularidade e produtividade científica, quais sejam: i) Analisar como se dá o imbricamento entre as três instâncias constitutivas do funcionamento da autoria (a pessoa; o escritor; e o inscritor) nas cartas privadas de Sêneca, Freud e John Wesley; ii) Analisar como se dá a constituição da paratopia nessas mesmas cartas privadas desses mesmos autores consagrados; e iii) analisar a emergência e a construção das possíveis cenografias nessas mesmas cartas privadas, desses mesmos autores consagrados, que são encenadas no e pelo discurso.

\section{Constituição do corpus}

O corpus de análise do projeto constitui-se de cartas privadas de autores consagrados dos campos discursivos filosófico, científico e religioso. Assim sendo, temos para o discurso filosófico as cartas privadas de Sêneca; para o discurso científico, as cartas privadas de Freud; já para o discurso religioso, temos as cartas privadas de John Wesley.

Nesse artigo, será analisada uma carta de Sêneca (autor consagrado do campo filosófico romano do século I).

\section{O funcionamento da autoria, a produção do espaço associado de um autor, a constituição da paratopia, a embreagem paratópica e a cenografia: perspectivas teóricas ${ }^{3}$}

Os processos de subjetivação que atuam na criação literária são tão complexos que, segundo Maingueneau (2012), não se pode reduzi-los a uma simples oposição entre escritor (alguém dotado de um estado civil) e enunciador (correlato de um texto). As teorias tradicionais que trabalham com essa tópica, são, para o autor, insuficientes e inoperantes, pois elas não levam em consideração o caráter constitutivo da instituição literária e, desse modo, não conseguem avaliar seu aspecto sistêmico, dinâmico, instável e paradoxal. De acordo com Dominique Maingueneau (2012), a palavra "escritor" (écrivain) é problemática, pois pode designar, ao mesmo tempo, uma profissão (a do escrivão) e/ ou uma figura associada a uma obra. A palavra "autor", por sua vez, já referenciaria uma condição social ou alguém que seria a fonte e o garante da obra. Entretanto, a noção de

2 Para mais detalhes dessa pesquisa, vide Referências, em que disponibilizo a referência bibliográfica de minha tese de doutorado (SOUSA JÚNIOR, 2018).

3 Como se trata de um desdobramento de minha tese, a parte teórica pode conter partes ipsis litteris da mesma. 
"enunciador" não é de uso comum. Segundo o autor, ela é um conceito linguístico recente e seu valor permanece ainda instável, podendo ser uma instância interior ao enunciado ou um simples locutor, aquele que produz o discurso:

O sujeito que mantém a enunciação, e se mantém por meio dela, não é nem o morfema "eu", sua marca no enunciado, nem algum ponto de consistência exterior à linguagem: "entre" o texto e o contexto, há a enunciação, "entre" o espaço de produção e o espaço textual, há a cena de enunciação, um "entre" que descarta toda exterioridade imediata. Não se podem dissociar as operações enunciativas mediante as quais se institui o discurso e o modo de organização institucional que ao mesmo tempo o pressupõe e estrutura. (MAINGUENEAU, 2012, p. 135).

Maingueneau (2012) afirma que o dispositivo institucional, os conteúdos manifestos e a relação interlocutiva que se mobilizam no interior do campo discursivo literário se entrelaçam e se sustentam mutuamente, legitimando e constituindo a cena de enunciação que os delimita. O autor afırma que qualquer que seja as formas de subjetivação do discurso literário, não se pode conceber sujeito biográfico e sujeito enunciador como duas entidades sem comunicação. Assim, Maingueneau (2012, p. 136) propõe distinguir três instâncias, ao invés de duas: a instância da pessoa, a instância do escritor e a instância do inscritor:

A denominação "a pessoa" refere-se ao indivíduo dotado de um estado civil, de uma vida privada. "O escritor" designa o ator que define uma trajetória na instituição literária. Quanto ao neologismo "inscritor", ele subsume ao mesmo tempo as formas de subjetividade enunciativa da cena de fala implicada pelo texto (aquilo que vamos chamar adiante de "cenografia") e a cena imposta pelo gênero do discurso: romancista, dramaturgo, contista... O "inscritor" é, com efeito, tanto enunciador de um texto específico como, queira ou não, o ministro da instituição literária, que confere sentido aos contratos implicados pelas cenas genéricas e que delas se faz o garante. A noção de "inscritor", apesar de sua etimologia, pretende escapar, tal como a de "inscrição", a toda oposição empírica entre escrito e oral: os enunciados da literatura oral também supõem "inscritores", ainda que sua estabilização se resuma à memória.

Essas instâncias não se apresentam em sequência, não há, em primeiro lugar, a pessoa (passível de uma biografia), em segundo, o escritor (ator do espaço literário) e em terceiro, o inscritor (sujeito da enunciação). Para Maingueneau (2012), essas instâncias são atravessadas umas pelas outras; cada uma delas sustenta as outras duas e viceversa, em um processo recíproco que dispersa e concentra o criador. As três instâncias constitutivas do funcionamento da autoria não se isolam, pois é na interrelação que elas dão condição ao desencadeamento do processo de criação: rompendo-se com uma das três instâncias, as duas outras sucumbem-se, uma vez que é através do inscritor que a 
pessoa e o escritor enunciam; é através da pessoa que o inscritor e o escritor vivem; e é através do escritor que a pessoa e o inscritor traçam uma trajetória no espaço literário.

Maingueneau (2012), com intuito de ampliar a distinção entre regime delocutivo e regime elocutivo e, dessa forma, negar a ideia dicotômica de texto literário/texto não literário, afirma que as produções de todo autor se vinculam a dois espaços indissociáveis, mas que não estão no mesmo plano: o espaço canônico e o espaço associado. Apresentarei, aqui, apenas o espaço associado. Para Maingueneau (2012), o espaço associado não pode ser concebido como equivalente à ideia de "paratexto" desenvolvida por Genette (1987), mas está mais vinculado ao regime elocutivo, cujas obras produzidas buscam comentar e interpretar as obras ditas "canônicas", para legitimá-las e constituí-las no interior do campo literário: é o caso das cartas privadas trocadas entre autores consagrados, dos prefácios, dos artigos publicados em jornais e revistas etc.

De acordo com Dominique Maingueneau (2012), a paratopia constitui e legitima a literatura (como um todo) e o autor (criador). Todo escritor só se torna, de fato, um criador, ao assumir sua condição paratópica. A paratopia está diretamente relacionada ao processo criador. O escritor não tem lugar determinado para se estabelecer, mas precisa negociar incessantemente um impossível lugar de adesão, uma vez que se constitui através da sua impossibilidade de obter uma topia; sua negociação entre o lugar e o não lugar é sempre difícil, o que dá condições de criação ao criador. A paratopia do autor, afırma Maingueneau (2012), está relacionada ao espaço literário e à sociedade. Todo escritor tem um modo singular de gerir seu posicionamento no interior do campo literário. A paratopia é um pertencimento paradoxal, ela não é nem condição inicial nem condição final, mas o processo, pois só existe paratopia ao se mobilizar atividade criadora e enunciação:

Nem suporte nem quadro, a paratopia envolve o processo criador, que também a envolve: fazer uma obra é, num só movimento, produzi-la e construir por esse mesmo ato as condições que permitem produzir essa obra. Logo, não há "situação" paratópica exterior a um processo de criação: dada e elaborada, estruturante e estruturada, a paratopia é simultaneamente aquilo de que se precisa ficar livre por meio da criação e aquilo que a criação aprofunda; é a um só tempo aquilo que cria a possibilidade de acesso a um lugar e aquilo que proíbe todo o pertencimento. Intensamente presente e intensamente ausente deste mundo, vítima e agente de sua própria paratopia, o escritor não tem outra saída que a fuga para a frente, 0 movimento de elaboração da obra. (MAINGUENEAU, 2012, p. 109).

A paratopia é do autor, mas ela só é criadora quando relacionada à figura do insustentável. A enunciação literária é justamente a negociação desse insustentável, dessa impossível tentativa de inscrição do autor na sociedade e no espaço literário que o circunscrevem. O escritor precisa escrever (criar) para legitimar sua situação paratópica, pois ele se encontra dentro e fora desse mundo. É no processo de criação que o escritor precisa 
apresentar sua condição insustentável, seu jogo de pertencimento e não pertencimento em uma topia. Maingueneau (2012) afirma que o escritor preserva sua paratopia escrevendo (produzindo). A paratopia criadora do autor é, ao mesmo tempo, a condição e o produto de uma criação.

Maingueneau (2012, p. 121) afırma que a relação texto e contexto se funda num dado constitutivo da enunciação literária: a obra precisa apresentar, no próprio mundo que constrói, suas condições de enunciação e seu caráter insustentável, paratópico. Pode-se falar, assim, "de uma espécie de embreagem do texto sobre suas condições de enunciação e, em primeiro lugar, sobre a paratopia que é seu motor".

O termo embreagem, que Maingueneau (2012) recupera da linguística, implica a consideração de um ou mais elementos linguísticos que inscreveriam no enunciado suas relações com a situação de enunciação. São, assim, denominados embreantes os elementos que participam, ao mesmo tempo, da língua e do mundo, ou seja, são signos linguísticos que adquirem determinado valor por meio do evento enunciativo que os produz. A partir dessa noção de embreagem linguística, o autor apresenta sua proposição de uma embreagem paratópica: elementos de variadas ordens que participariam, ao mesmo tempo, do mundo criado pela obra e da situação paratópica do autor, que é condição e produto da criação literária.

A cenografia, por sua vez, Maingueneau a define como sendo a cena de fala construída no/pelo texto. A cenografia não é uma simples decoração, ou seja, não se trata somente de uma questão de estilística linguística, ela é um aspecto legitimador da enunciação, da construção do texto, mas também é legitimada por essa mesma enunciação: o enunciador instaura, através de sua enunciação, a situação, o mundo a partir do qual ele pretende "mostrar-se" e, ao mesmo tempo, legitimar sua enunciação. A cenografia se apoia, especificamente, nesse tipo de funcionamento.

Desse modo, para o autor, uma cenografia só se desenvolve plenamente se o locutor puder controlar seu desenvolvimento. Em um enunciado monologal, por exemplo, Maingueneau (2015) afirma que o locutor tem domínio de todo o processo enunciativo, o que dá a possibilidade de construção de cenografias mais ou menos estáveis, "duras" (rígidas) e controladas, o que não acontece nos diálogos, em uma interação oral, por exemplo, em que os locutores (participantes) não conseguem impor, manter, nem controlar uma mesma cenografia ao longo de todo o processo de interação oral no qual estão envolvidos. Isso se dá devido às situações enunciativas imprevisíveis as quais os interlocutores precisam reagir instantaneamente e espontaneamente, no caso da interação oral.

No texto Cenografia epistolar e debate público, Maingueneau (2008) afirma que a cenografia é um tipo de "armadilha" para o leitor, pois, se a cenografia for bem explorada, o leitor receberá o texto como sendo o texto encenado pela cenografia e não como o texto 
previsto pela cena genérica em si. Nesse sentido, a escolha da cenografia não é alheia nem indiferente, pois o discurso, posicionando-se a partir de sua cenografia, pretende convencer instituindo a cena de enunciação que o legitima. Segundo o autor, o discurso impõe sua cenografia desde o início, mas, ao mesmo tempo, é através de sua própria enunciação que ele poderá legitimar essa mesma cenografia:

Para desempenhar plenamente seu papel, a cenografia não deve, portanto, ser um simples quadro, um elemento de decoração, como se o discurso viesse ocupar o interior de um espaço já construído e independente desse discurso: a enunciação, ao se desenvolver, esforça-se por instituir progressivamente seu próprio dispositivo de fala. Ela implica, desse modo, um processo de enlaçamento paradoxal. Desde sua emergência, a palavra supõe certa situação de enunciação, a qual, com efeito, é validada progressivamente por meio dessa mesma enunciação. Assim, a cenografia é, ao mesmo tempo, origem e produto do discurso; ela legitima um enunciado que, retroativamente, deve legitimá-la e estabelecer que essa cenografia de onde se origina a palavra é precisamente a cenografia requerida para contar uma história, para denunciar uma injustiça etc. Quanto mais o coenunciador avança no texto, mais ele deve se persuadir de que é aquela cenografia, e nenhuma outra, que corresponde ao mundo configurado pelo discurso. (MAINGUENEAU, 2008, p. 118).

\section{Análise de uma das cartas de Sêneca (Discurso Filosófico)}

Lucius Annaeus Seneca, ou apenas Sêneca, foi um dos mais célebres advogados, escritores e intelectuais do Império Romano. Foi também conhecido pelo seu pensamento filosófico, o Estoicismo, que buscava negar, de alguma maneira, o pensamento filosófico epicurista.

De acordo com Moura (2015), as cartas de Sêneca a Lucílio parecem encenar um solilóquio, demonstrando uma preocupação com o ensinamento filosófico. O autor afirma o seguinte:

As Epsitolae Morales são uma obra do final da vida de Sêneca, escritas ao que tudo indica entre os anos de 62 e 65, após o afastamento do autor das atividades políticas. As cartas aparentemente estão organizadas na ordem que foram escritas (como fica sugerido em diversas passagens, e.g. Ep. 10.1), são dirigidas a um certo Lucílio, que nos é conhecido apenas da obra do filósofo. (MOURA, 2015, p. 1).

Segundo Segurado e Campos (SÊNECA, 2004), é possível conceber essas cartas privadas como cartas reais, não uma criação ficcional/literária de Sêneca, ou seja, uma produção 
do seu espaço canônico. Há indícios e registros de outras cartas privadas do autor com outros destinatários diferentes de Lucílio. Nessa perspectiva, pode-se afirmar que essas cartas privadas funcionam como um gênero do discurso (uma cena genérica) e uma produção do espaço associado de Sêneca, pois, a partir de seu posicionamento e das condições sócio-históricas de produção que legitimaram a enunciação dessas cartas, Sêneca comenta, por exemplo, por meio da prática discursiva da troca dessas cartas, sobre suas obras canônicas de cunho filosófico em que apresenta seu pensamento estoico, as legitimando. Além disso, com tal prática, ele busca também legitimar sua identidade criadora e o seu posicionamento no interior do campo filosófico que o circunscreve. Segurado e Campos (SÊNECA, 2004, p. X e XI) afirma:

As cartas de Séneca situam-se, digamos, a meio caminho entre o primeiro e o segundo dos tipos de cartas referidos: são uma correspondência real entre dois amigos em que, na quase totalidade dos casos, são desenvolvidos por Séneca diversos problemas de índole filosófica. As cartas a Lucílio não foram as únicas que Séneca escreveu e publicou. [...] Em contrapartida conserva-se uma coleção de cartas pretensamente trocadas entre Séneca e S. Paulo, decerto devida ao facto de Séneca ser bastas vezes citado com apreço por diversos Padres da Igreja.

A carta a ser analisada nesse artigo é a Carta 2 de Sêneca para Lucílio. Em relação ao funcionamento da autoria ${ }^{4}$, na instância da pessoa (os dados biográficos e questões íntimas do autor trespassam na enunciação), o autor apresenta uma certa afeição ao seu interlocutor: "Tanto aquilo que me escreves como o que oiço dizer de ti fazem-me ter boas esperanças a teu respeito" (SÊNECA, 2004, p. 3). Mostra também como agiria em certas ocasiões: "É isso o que eu mesmo faço: de muita coisa que li retenho uma certa máxima" (p. 4). A importância de analisar e articular os aspectos íntimos e biográficos do sujeito da enunciação é, para Maingueneau, uma maneira de negar o caráter autotélico dado à obra pelos estudos da área da Literatura, que consideram a produção de um autor como absoluta (se bastando por si mesma). O autor de uma obra literária (nesse caso, uma obra filosófica) é concebido, nessa perspectiva de Maingueneau, como um sujeito (que também existe em carne e osso e vive em sociedade) que realiza práticas discursivas em busca da legitimação e constituição do seu posicionamento no interior do campo onde busca sua inscrição e sua inserção.

Desse modo, Sêneca é também um sujeito de carne e osso que busca, por meio de suas práticas discursivas (como a troca de cartas privadas, por exemplo), legitimar e constituir seu posicionamento estoico no interior do campo filosófico romano do século I.

4 Sabe-se que a noção de autoria e toda sua problematização ainda não eram pensadas na época de Sêneca (final do século I), todavia, o conceito proposto por Maingueneau se mostra produtivo e funcionando adequadamente nas cartas privadas trocadas pelo filósofo em questão. 
Atrelada à instância da pessoa está a instância do escritor (um ator que define uma trajetória na instituição literária). O autor busca legitimar e constituir o estoicismo, a Filosofia Estoica, no interior do campo filosófico romano do final do século I. Para o estoicismo, só aquilo que é necessário e suficiente é o correto, o justo, a moral (a comida, por exemplo, é a única coisa necessária e suficiente para saciar a fome, não importa se ela é apanhada do pé de uma árvore, se servida em louças de prata e ouro etc.). Nessa carta privada, o autor defende a necessidade e a suficiência de se ter poucos livros (somente aqueles estritamente necessários), de ler poucos pensadores (somente os de confiança, os mais relevantes), de retomar as leituras já feitas, pois a justa medida não é o exagero das coisas, a sua dispersão, mas o uso eficiente, a concentração, somente aquilo que basta. É, assim, por meio da prática discursiva da troca de cartas privadas que Sêneca consegue apresentar e discutir sobre o estoicismo. Com tal prática, Sêneca consegue legitimar e constituir seu posicionamento, pois ao enunciar sobre a filosofia estoica em cartas, ele pretende, por meio do processo de enunciação e de produção delas, se mostrar enquanto um filósofo e além, se mostrar como alguém que engendra um pensamento filosófico inédito no interior do campo filosófico em que busca sua inscrição.

Sêneca busca se legitimar e se constituir enquanto autor da instituição filosófica onde pretende ter sua inscrição (sempre difícil), percorrendo-a, dentre outras maneiras, através da prática da troca de cartas privadas, que, ao legitimar seu estatuto de autor/filósofo, tal estatuto também o legitima a produzir e a apresentar sua filosofia por meio da enunciação das cartas. Eis o trecho dessa carta privada que evidencia a emergência da instância do escritor:

Toma, porém, atenção, não vá essa tua leitura de inúmeros autores e de volumes de toda a espécie [...]. Importa que te fixes em determinados pensadores [...] se na verdade queres que alguma coisa permaneça definitivamente no teu espírito. Estar em todo o lado é o mesmo que não estar em parte alguma! [...] Demasiada abundância de livros é fonte de dispersão. (SÊNECA, 2004, p. 3).

Da mesma forma, atrelada também às duas outras instâncias, a instância do inscritor (implica uma relação subjetiva do escritor com o gênero do discurso que ele mobiliza e a cenografia construída no/pelo texto). Sêneca se vale de máximas como uma forma de posicionar-se em relação às instâncias do gênero e do texto, assumindo ser a apresentação de máximas adequada ao gênero/texto por meio do qual enuncia o que garante a legitimação do seu estatuto de autor e filósofo, pois ele busca, com a mobilização das máximas, a partir do seu posicionamento, se afirmar como um exímio pensador do campo filosófico. A seguir, excertos de cartas do autor mostrando a regularidade da apresentação de máximas: "A minha máxima de hoje encontrei em Epicuro" (SÊNECA, 2004, p. 4); "Para finalizar esta carta, aqui te deixo uma máxima que li hoje" (SÊNECA, 2004, p. 9); mais outra carta: "Conforme dizia o nosso Átalo, 'a maldade bebe ela mesma a maior parte do seu veneno'!" (SÊNECA, 2004, p. 356). 
Em relação à constituição da paratopia, que também está atrelada às três instâncias constitutivas do funcionamento da autoria, Sêneca, nessa carta privada, busca legitimar seu posicionamento estoico, ou seja, constituir sua filosofia no interior do campo, mas a negociação é sempre difícil, impossível, entre o lugar e o não lugar. Desse modo, mesmo precisando negar a filosofia epicurista (de Epicuro), posicionamento que era dominante no interior do campo filosófico romano da época, para legitimar seu posicionamento estoico, o autor necessita, contraditoriamente, se valer de máximas do próprio Epicuro (eis sua paratopia). Sêneca se vale, assim, de Epicuro para defender seu ideal do contentar-se com o suficiente (um dos pressupostos de seu pensamento filosófico).

O processo de enunciação dessa carta privada se legitima e se constitui, então, pela paratopia do autor, pelo caráter insustentável, insuficiente do autor, que, na negociação entre a sociedade e o espaço filosófico que busca sua inscrição, se vale de subterfúgios para explicar sua pequena contradição, isto é, apresentar sua paratopia. É por meio da enunciação das cartas que o autor cria o mundo ao qual apresenta sua condição paratópica, ou seja, é através da prática discursiva da troca de cartas e de seu próprio processo produtivo que Sêneca expõe suas desculpas e contradições. Eis o excerto dessa carta privada em que mostra o funcionamento e a constituição da paratopia do autor: "A minha máxima de hoje encontrei em Epicuro (é um hábito percorrer os acampamentos alheios, não como desertor, mas sim como batedor!). Diz ele: É um bem desejável conservar a alegria em plena pobreza" (p. 4).

A construção das cenografias possíveis dessa carta privada de Sêneca, por sua vez, se apresenta como exógena (em que se distancia da rotina genérica do gênero do discurso ao qual está mobilizado). Nessa perspectiva, observamos que essa carta privada encena várias coisas: uma espécie de guia prático para a frugalidade; um debate filosófico; uma aula (de tom professoral); um aconselhamento moral; um mestre ensinando seu discípulo. De acordo com Moura (2015, p. 3):

As Cartas apresentam-se desde o início como uma forma de aconselhamento moral (a Ep. 1.4 já contém o verbo praecipio, "prescrevo", "recomendo", "ensino"). As numerosas objeções e perguntas atribuídas a Lucílio pelo próprio Sêneca colocam aquele no papel de pupilo ainda em dúvida quanto à importância da filosofia, e este no papel de professor (e.g. a Carta 89 é uma exposição dos diversos ramos da filosofia, supostamente a pedido de Lucílio). Vários tópicos específicos de filosofia são apresentados enquanto resposta a um questionamento do destinatário e, em diversas ocasiões no decorrer das Epistulae, Sêneca sugere que Lucílio ainda não conseguiu se livrar das ocupações mundanas para se entregar por inteiro à busca da virtude, objetivo de que o filósofo o lembra constantemente. Ensinar o outro por vezes assume um papel de tão grande destaque, que se torna praticamente a justificativa de todo conhecimento (Ep. 6.4). 
Desse modo, todas as cenografias construídas nas e pelas cartas privadas de Sêneca legitimam e constituem seu processo enunciativo, sua prática discursiva e, consequentemente, seus enunciados, assim como todos estes fatores também legitimam e constituem as cenografias construídas, pois é através das encenações supracitadas que Sêneca busca forjar sua identidade criadora (seu estatuto de autor/filósofo) e legitimar suas produções do espaço canônico e associado no interior do campo filosófico romano do final do século I. Eis um excerto dessa carta privada de Sêneca a Lucílio, como exemplo que evidencia isso:

E com razão, pois se há alegria não pode haver pobreza: não é pobre quem tem pouco, mas sim quem deseja mais. Que importa o que temos no cofre, ou nos celeiros, quantas cabeças de gado ou quanto capital a juros, se fizermos as contas não ao que possuímos, mas ao que queremos possuir? Queres saber qual a justa medida das riquezas? Primeiro: aquilo que é necessário; segundo: aquilo que é suficiente! (SÊNECA, 2004, p. 4).

\section{Considerações finais}

A partir da análise da carta privada de Sêneca, percebe-se que há indícios de sustentação da minha hipótese central. Além disso, a prática discursiva da troca de cartas privadas de autores consagrados dos discursos constituintes, enquanto cena genérica e produção do espaço associado, embreia o texto em seu contexto. Ademais, essa prática discursiva busca, ao mesmo tempo, legitimar e constituir o estatuto de autor/filósofo de Sêneca, o seu pensamento/posicionamento filosófico estoico e suas produções (do espaço canônico e associado).

Essas cartas privadas de Sêneca podem funcionar, assim, como embreantes paratópicos, pois estão para além da ideia de uma carta íntima, na medida que instauram um posicionamento e gerem a relação entre os integrantes da comunidade discursiva filosófica estoica. Nesse sentido, tais cartas privadas não se restringem, exclusivamente, a suas rotinas genéricas, pois, ao mesmo tempo em que Sêneca fala de si, ele fala também do seu posicionamento discursivo.

\section{REFERÊNCIAS}

GENETTE, G. Seuils. Paris: Seuil, 1987.

MAINGUENEAU, D. Discurso literário. 2. ed. São Paulo: Contexto, 2012.

MAINGUENEAU, D. Cenas de enunciação. Organização Maria Cecília Pérez de Souza-eSilva e Sírio Possenti. São Paulo: Parábola Editorial, 2008. 
MAINGUENEAU, D. Discurso e análise do discurso. Tradução Sírio Possenti. São Paulo: Parábola Editorial, 2015.

MOURA, A. R. de. Diálogo interior nas Cartas a Lucílio, de Sêneca. Ágora. Estudos Clássicos em debate 17. 2015. Disponível em: http://www2.dlc.ua.pt/classicos/17/11. dialogointerior.pdf. Acesso em: 31 ago. 2019.

SÊNECA, L. A. Cartas a Lucílio. Tradução, Prefácio e Notas de J. A. Segurado e Campos. Lisboa: Fund. Caloveste Gulbenkian, 2004.

SOUSA JÚNIOR, M. J. V. de. A carta privada de autores consagrados do campo literário: uma abordagem da cena genérica como embreante paratópico. 2018. Tese (Doutorado em Estudos Linguísticos) - Instituto de Letras e Linguística, Universidade Federal de Uberlândia, Uberlândia, 2018. Disponível em: http://dx.doi.org/10.14393/ufu. te.2018.627.Acesso em: 31 ago. 2019. 